\title{
Políticas curriculares e a base nacional comum curricular: emancipação ou regulação?
}

\author{
Curricular policies and the common curricular national basis: \\ emancipation or regulation?
}

Maria de Lourdes Pinto de Almeida Universidade do Oeste de Santa Catarina

Hildegard Susana Jung Universidade La Salle

\section{RESUMO}

Este artigo é fruto de pesquisa bibliográfica e documental sobre a Base Nacional Comum Curricular. O objetivo é refletir sobre o documento em vigor no contexto das políticas educacionais, seguindo a metodologia histórico-crítica. Enquanto instrumento de regulação da educação com uma maquiagem de legislação, apresenta-se como caminho para a emancipação humana no sistema capitalista. Foram encontrados pontos de regulação na Base Comum a todos, pois a seleção de determinados conteúdos em detrimento de outros denuncia a visão de um grupo dominante acerca do que seja legítimo ensinar, num exercício de regulação a serviço de uma Pátria panóptica. Os fundamentos científicos, metodológicos, filosóficos e pedagógicos da proposta do Estado, ainda que questionem a tradicional integração das disciplinas e resgatem temas como a ética e a justiça, tornam a escola um cenário midiático, com apelo às estratégias televisivas de entretenimento, em que não especialistas falam sobre tudo.

Palavras-chave: Currículo mínimo nacional; Educação básica; Políticas públicas em educação.

\section{ABSTRACT}

This article is the fruit of bibliographical and documentary research on a National Curricular Common Base. The objective is to reflect on the document in force in the context of educational policies, following a historical-critical methodology. As an instrument of regulation of education with a makeup of legislation, it presents itself as a path to a human emancipation in the capitalist system. Regulatory points were found in the Common Base for all, for a selection of certain contents over other denunciates a view of a dominant group on what is legitimate to teach, in an exercise of regulation of a panoptic country service. The scientific, methodological, philosophical and pedagogical foundations of the State's proposal, although they question a traditional 


\section{Disn \\ 15SN: 1984-6444

approach of the disciplines and the subjects as an ethics and justice, they make the school a media scenario, with an appeal to the entertainment televisions, in which nonspecialists about everything.

Keywords: National minimum curriculum; Basic education; Public policies in education.

\section{Considerações preliminares}

O estabelecimento de uma Base Nacional Comum Curricular tem sido um projeto que se desenvolve juntamente com a implementação de propostas liberais para a educação e que visam adequar o ensino às exigências da administração capitalista. Bianchetti (1996, p. 94) destaca duas teorias como basilares nas propostas neoliberais. A primeira seria a do capital humano. Segundo esta, a função da escola se reduz à formação de recursos humanos para a produção econômica: "nessa lógica, a articulação do sistema educativo com o sistema produtivo deve ser necessária. $\mathrm{O}$ primeiro deve responder de maneira direta à demanda do segundo". A outra teoria refere-se à redução da política à lógica do mercado, em que as políticas públicas passam a ser premiadas (com a moeda política corrente, o voto) ou não, conforme sua eficácia em oferecer os bens públicos: por um lado se preocupa com a “organização do aparelho de produção dos bens públicos, por outro, com sistema de pressão, sanção e recompensa que determinam o comportamento dos agentes que concorrem à produção dos "bens públicos"” (Idem). Com isso, ocorre um fenômeno de despolitização das mais diversas esferas da sociedade, aí incluídas a escola e o próprio Estado. Assim, a reflexão sobre este tema deve ser feita sobretudo a partir da análise do pano de fundo econômico e ideológico dos tempos de globalização.

Resultante de pesquisa bibliográfica com natureza qualitativa, este artigo dedica-se a analisar, no cenário anteriormente descrito, o impacto da implantação de uma Base Nacional Comum Curricular na Educação Básica brasileira, no contexto das políticas curriculares, questionando se a mesma poderá ser condutora de um projeto de emancipação ou regulação. Para explicitar os papéis da educação na sociedade liberal contemporânea fazemos um breve histórico das doutrinas liberais. Assim, fazemos uma correlação entre elementos históricos e conceituais que são básicos 


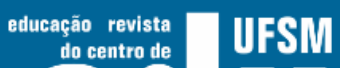

para compreender o liberalismo, com base na teoria marxista, considerando em suas formulações as origens materiais e históricas de classe, os antagonismos presentes na luta de classe, bem como a importância da luta pela consciência de classe no processo de transformação da sociedade capitalista.

Em um segundo momento, examinamos os impactos do estabelecimento de uma Base Nacional Comum Curricular, sem desprezar os antecedentes históricos desta conjuntura. No interior deste debate, além da questão ideológica, a análise se dá levando em conta as categorias Regulação e Emancipação.

\section{O credo liberal - Um breve histórico}

Na concepção liberal e neoliberal se dá ênfase aos indivíduos como agentes racionais cuja realização dos interesses promoveria o bem comum. Não vamos entrar na discussão do que vem a ser o bem comum. Entretanto, para um liberal coerente, ele é sempre o resultado da agregação de escolhas individuais e o mercado é exatamente o mecanismo natural articulador dessas escolhas. O liberal concebe 0 bem comum como um a posteriori. Assim, a educação deve estar de certo modo articulada com a ação individual, de modo a promover a sua racionalidade, preparando indivíduos aptos para atuarem competitivamente, conforme o funcionamento do próprio mercado.

O liberalismo como o ideário do livre mercado tem encontrado defesas radicais, no sentido de se fazer valer a maravilha da livre iniciativa privada. Na sua vertente mais radical propõe-se o princípio da redução máxima do papel do Estado, ou o Estado mínimo. Trata-se da admissão da soberania do mercado que, conforme seus gurus, impõe a privatização do ensino em todos os níveis e a eliminação da intervenção ou investimento do Estado num setor que tem sido tão lucrativo, quando submetido à iniciativa privada. O liberalismo surgiu em contraposição às doutrinas mercantilistas que, mesmo admitindo a limitação das regulamentações internas, eram mais favoráveis a uma política governamental ativa, destinada a aumentar a participação nacional nos mercados internacionais. Os liberais, a partir dos fisiocratas e de Adam Smith, radicalizaram o princípio da liberdade interna e ainda mais na esfera 


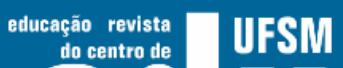

externa.

O credo liberal foi-se afirmando graças à industrialização, frente aos princípios da ética paternalista católica e do mercantilismo. Nesse sentido, o individualismo inerente ao liberalismo clássico tornou-se a ideologia dominante do capitalismo, cujos princípios norteadores foram o egoísmo, a frieza calculista e o atomismo (HUNT; SHERMAN, 1977), movidos pelos impulsos egoístas de maximizar sua felicidade, isto é, diminuir o sofrimento e aumentar os prazeres. A. Smith (1985), o grande sistematizador do ideário liberal, por exemplo, dizia que devemos esperar o pão, não da bondade do padeiro, mas do seu egoísmo, pois seria pensando em aumentar os seus lucros e não em fazer uma boa ação que ele se empenharia em produzir suas mercadorias.

Atualmente, o capitalismo tem sua expressão ideológica maior no denominado neoliberalismo. Essa nova versão da ideologia capitalista radicaliza a proposta de redução das funções do Estado. O Estado mínimo significa redução máxima do poder público na economia. Propõe-se um total desmantelamento dos sistemas públicos voltados para atender os setores sociais, como os subsídios, investimentos diretos e regulamentação das atividades econômicas. Prega-se a desmontagem do sistema público de previdência social e a privatização das empresas estatais. A antiga noção de investimento público em setores estratégicos não faria mais sentido para os neoliberais. No que respeita ao comércio internacional, as nações mais poderosas pregam uma total liberação de fronteiras e tarifas, se bem que, na verdade, eles continuam mantendo uma série de medidas protecionistas, que não se limitam às restrições do dumping social, mas a uma série de cobranças de taxas diretas e indiretas que acabam incidindo sobre os interesses dos parceiros comerciais, principalmente os mais fracos. Em seus artigos na Folha de São Paulo, L. Nassif tem denunciado essas práticas escusas ${ }^{1}$. Os governos que mais se identificaram com as práticas neoliberais foram os de Margaret Thatcher, na Inglaterra, e Ronald Reagan, nos Estados Unidos.

\footnotetext{
1 Ver principalmente o artigo "O protecionismo americano" em que analisa as barreiras não tarifárias implementadas pelos americanos para conter o fluxo de entrada de mercadorias do Brasil. NASSIF, L., In: Folha de são Paulo, 14/10/97.
} 


\section{F WEM oltuarao}

Segundo Oliveira (1996, p. 57), nem mesmo os professores deveriam estar defasados em função dessas novas possibilidades para uma renovação do projeto pedagógico, devendo se adequar às novas condições: "decisão política (delineamento de prioridades e destinação de recursos financeiros); formação de uma rede de formadores; visão do professor como produtor e consumidor do conhecimento", ou seja, integrando uma rede de pesquisa e comunicação. Historicamente, a hegemonia do novo modelo reticular estaria em conformidade com a passagem de uma sociedade que exigia uma formação massificada que se adaptasse bem ao modelo produtivo vigente, que "requeria um grande número de trabalhadores para tarefas rotineiras a serem executadas sem questionamento" (OLIVEIRA, 1996, p. 57). Valoriza-se agora o trabalhador polivalente, capaz de atuar em equipe (em rede), bem como disponível para atuar em diversos setores, até mesmo para viajar ou trabalhar conectado em uma rede de comunicação como as nets virtuais, ou seja, cabe à educação preparar um trabalhador não mais para obedecer e agir conforme "ordens", mas para saber lidar com o imprevisível, para saber adaptar-se às novas situações, enfim, para inovar.

A Educação deve representar a práxis reflexiva possibilitadora de socialização do conhecimento e da participação democrática, ou seja, de 'noções concretas' de elaboração intelectual dos alunos, professores e da comunidade. Não se trata apenas de uma nova escola, mas sim de outra, com significação para além da gestão neoliberal e, portanto, voltada para a vida, para a realidade histórica desse tempo que se chama hoje.

\section{A Base Nacional Comum Curricular: uma análise para além da regulação da Educação}

A discussão sobre os conteúdos que deveriam compor o Currículo da escola popular acentuou-se na segunda metade de século XIX e, de acordo com Souza (2000, p. 9), essa temática já trazia consigo a ideia de universalização. Ainda assim, continua a autora, "diferentes interesses políticos ideológicos, religiosos, sociais, econômicos e culturais" tencionavam as negociações. Internacionalmente, circulava a ideia de que a escola poderia gerar progresso, mudança social e modernização, e os 


\section{Disn

congressos, livros e artigos disseminavam estes modelos. Neste contexto de final de século XIX, conforme explica Petitat (1994), a maioria dos países, principalmente os mais desenvolvidos e aqueles em desenvolvimento, massificavam a escolarização, com vários aspectos em comum: a obrigatoriedade, a educação como responsabilidade do Estado, "a secularização do ensino e a secularização da moral, a nação e a pátria como princípios norteadores da cultura escolar, a educação popular concebida como um projeto de integração ideológica e política" (SOUZA, 2000, p. 11) e uma homogeneidade nos currículos.

Cabe aqui refletir que adotar uma concepção de currículo impõe conciliar a ambivalência atinente à natureza humana, à diversidade presente no espaço escolar. Entende-se que, anterior ao debate de uma Base Curricular há que questionar e definir: que tipo de conhecimento vale mais? Num mundo complexo e plural diferentes comunidades argumentativas precisam estabelecer-se, ter vez e voz. O conhecimento e a produção não podem ser deslocados das formas de ser e de conviver dos homens. Nesta perspectiva "a norma para o currículo, portanto, não é consenso, a estabilidade e o acordo, mas o conflito, a instabilidade, o desacordo, porque o processo é de construção seguido de desconstrução seguido de construção" (CHERRYHOLMES, 1988. p. 149). As concepções de currículo são reflexões que interessam ao debate de uma base curricular, já que atribuem sentidos e significados e refletem contextos educacionais.

No Brasil, o debate em torno de uma Base Nacional Comum Curricular tem ocupado especial espaço na mídia durante os anos de 2015 e 2016 (este último, principalmente). A razão de o assunto ter retornado à pauta se deve a que o Plano Nacional de Educação (PNE), lei n 13.005, de 25 de junho de 2014 prevê, como estratégia 2 da meta 2 "pactuar entre União, Estados, Distrito Federal e Municípios, no âmbito da instância permanente de que trata $0 \S^{5^{\circ 2}}$ do art. $7^{\circ}$ desta Lei, a implantação" dos objetivos que virão a configurar a Base Nacional Comum Curricular do Ensino Fundamental. Dizemos que o assunto retornou à pauta, porque na verdade

\footnotetext{
2 "§5o: Será criada uma instância permanente de negociação e cooperação entre a União, os Estados, o Distrito Federal e os Municípios" (BRASIL, 2014).
} 


\section{Disn

desde a promulgação da Lei de Diretrizes e Bases (LDB), Lei 9.394, de 20 de dezembro de 1996, a criação de uma BNC é "prato do dia" nas articulações políticas relacionadas com a educação.

No centro da discussão a respeito da BNCC, indo mais além da questão ideológica, ensejamos analisá-la à luz das categorias Regulação e Emancipação. Assim, questionamos: A Base Nacional Comum Curricular promove emancipação, ou na verdade representa um importante instrumento de regulação? Tendo presente que “a realidade não se exaure na imagem física do mundo" (KOSIK, 1976, p. 25), a constatação de que a composição da BNCC está tomada de componentes ideológicos - bem como, em grande medida, as políticas educacionais brasileiras de maneira geral, independentemente do período histórico -, leva-nos ao encontro de uma concepção de regulação. A regulação, aliás, passa a ser um dos papeis do Estado a partir dos preceitos neoliberais que são incorporados pela educação a partir dos anos de 1990, inclusive por meio da nossa LDB 9394/96, com acento claramente descentralizador (JUNG e SUDBRACK, 2016).

Levando em conta os elementos ideológicos reguladores constantes das políticas públicas educacionais, incluindo as curriculares e a nova Base Nacional Comum Curricular que aqui discutimos, cabe uma reflexão importante: qual é o impacto destas políticas e, principalmente, da nova Base Nacional Comum Curricular na Educação Básica brasileira? Elas representam uma oportunidade de emancipação? Ou manipulam a educação de maneira que a mesma se submeta cada vez mais à regulação da "Pátria Panóptica³?" (JUNG e SUDBRACK, 2016).

Segundo Roio (in: SCHLESENER, 2014, p. 128), "A escola é então um elemento importante na constituição do conformismo social, da hegemonia de uma classe sobre a outra ou, para sermos mais explícitos, da dominação política e econômica". Desta maneira, nos questionamentos com Alves (2014, p. 1467 e 1468): "O que é mesmo uma BNCC ${ }^{4}$ ? [...] Precisamos de uma BNCC?". Reconhecendo a

\footnotetext{
3 "O termo panóptico, recuperado de Bauman (2001), que, por sua vez, o tomou emprestado de Foucault (1926-1984), serve como metáfora para o poder da modernidade" (JUNG e SUDBRACK, 2016, p. 271).

${ }^{4}$ Base Nacional Comum Curricular.
} 


\section{DFM \\ ISSN: $1984-6444$

dificuldade de definir o que seria hoje uma Base Nacional Comum Curricular, a autora esclarece que questionar esta base relaciona-se com diversos aspectos: a) existe, internacionalmente, uma ideia de que poderia haver um currículo nacional padronizado para vários países - longe de dissenso ou consenso, aqui nos parece que há um contrassenso: como pode um currículo ser nacional, se a pretensão é uniformizá-lo em diversos países? Talvez avaliações externas em grande escala como o Programme for International Student Assessment (PISA) tenham alguma coisa a ver com isso -; b) a persistente ideologia de Comenius (1592-1670) "precisando de um ensino igual para todos - o ler, escrever e contar" (ALVES, 2014, p. 1468); c) a universalização trouxe para dentro das escolas as minorias diferentes, às quais os governos têm dificuldades de atender, e não houve êxito na preparação de professores para atuar neste novo ambiente.

Dentro deste contexto, ao lado das questões antes citadas, ainda há uma enorme máquina internacional de "vendas de produtos da educação: bases nacionais, provas, apostilas, etc." (ALVES, 2014, p. 1469) a serviço, também, da lógica da Qualidade Total (Total Quality Management -TQM). A questão da qualidade, portanto, e a suposta crise do sistema é uma das múltiplas demandas às quais responde a defesa de uma Base Nacional Curricular Comum atrelada às tendências curriculares de um mundo globalizado e que, por intermédio dos preceitos neoliberais, passou a tratar a educação com a lógica do mercado ${ }^{5}$. As grandes corporações parceiras do MEC vinculam a qualidade da educação à centralização de um currículo comum, de maneira que se sentem à vontade, inclusive, para criar novas formas de governabilidade, como por exemplo uma espécie de desestatização da educação. Esta, a educação, passa a uma lógica edu-business, cujas consequências para os professores são a responsabilização, a pressão por resultados e, no caso de as metas não serem alcançadas, de punição e penalização. Em outras palavras: o controle panóptico - sobre a ação pedagógica é total.

Os reflexos da Base Nacional Curricular Comum para a Educação Básica de

5 Total Quality Management ou simplesmente TQM, supõe "noções de melhor preço, ausência de defeitos, obediência ao projeto, adequação ao uso e satisfação do cliente por meio de melhoria contínua nos produtos e serviços oferecidos" (TURCHI, 1997, p. 16). 


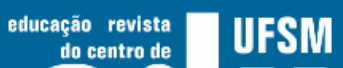

uma maneira geral, portanto, resultam amplamente reguladores. Nesse sentido, é necessário questionar: "como transformar o mundo dos homens, como vislumbrar a emancipação humana?" (ROIO, in: SCHLESENER, 2014, p. 129). O ponto de partida, segundo o autor, é a superação da cultura burguesa e a promoção de um significativo progresso intelectual, o qual levará o homem à emancipação. Este processo se dará pela educação enquanto instrumento de luta e de desenvolvimento social e humano. Vale a pena destacar que, diante de tudo isso, a força que move os interesses intelectuais tem suas raízes na base social econômica e isto não pode ser esquecido, principalmente quando se discutem reformas educacionais escolares. Para construirmos uma análise ou mesmo uma crítica temos que fazê-las inseridas em um quadro de forças reguladoras, pensando na luta de classes dentro desse quadro, nunca negando a força da história.

\section{(Des) Considerações finais}

A interação da educação com o mercado é complexa e sua compreensão exige uma reflexão com vários vieses. Perante a noção de que o mercado é o único soberano, como acreditam os liberais e, conforme se propõem as diretrizes políticas nacionais recentes, a educação tem sido cada vez mais vista como um elemento da engrenagem do mercado ao preparar indivíduos para agirem conforme sua racionalidade, bem como ao se tornar ela mesma uma mercadoria. Com isso, a tendência das políticas liberais é a de suprimir a educação enquanto um bem público. A educação torna-se apenas mais um nó na "rede" chamada mercado.

No entanto, a educação deverá comprometer-se com o conhecimento para além da informação, como prática consciente que alude à participação de alunos, mestres e gestores. Isso implica, portanto, em unir educação e vida para uma autêntica pedagogia da promoção humana, uma pedagogia claramente emancipatória à qual o nexo instrução-educação seja um trabalho dos sujeitos de uma Instituição Educacional. A articulação de propostas coletivas parece-nos tornar o espaço escolar o lugar no qual os alunos não negligenciam as noções concretas do conhecimento, porém não ficam enchendo a cabeça com fórmulas e palavras que não têm sentido e 


\section{Uism \\ ISSN: 1984-6444

logo cairão no esquecimento (SAVIANI, 1993). Exatamente o contrário do que propõe a Base Nacional Comum Curricular.

Restaria uma esperança. Quem sabe o movimento de discussão e de reflexão em torno da Base Nacional Curricular Comum não suscitaria aquilo que Gramsci denominou de "Catarse". Saviani expressa este termo como a superação do senso comum pela consciência filosófica, em que ocorreria "a passagem de uma concepção fragmentária, incoerente, desarticulada, implícita, degradada, mecânica, passiva e simplista a uma concepção unitária, coerente, articulada, explicita, original, intencional, ativa e cultivada" (SAVIANI, 1993, p. 10). Mas a posição de Saviani é formulada dentro de uma outra corrente reguladora e hegemônica, oposta ao liberalismo. A proposta atual da Base Nacional Curricular Comum vai ao encontro dos princípios metodológicos e ideológicos inerentes à atual regulação do sistema liberal, cuja supremacia tem sido imposta a todos os setores das sociedades mundiais. Resta saber até que ponto essa proposta ofereceria elementos que poderiam ser resgatados por uma análise crítica, tornando-os instrumentos para uma perspectiva coerente com os anseios dos oprimidos e excluídos não no sentido de integração num sistema excludente por natureza, mas conforme as possibilidades de se transformá-lo radicalmente.

A compreensão dos processos político-educativos como processos emancipatórios possibilita, em alguma medida, o papel do intelectual como parte de um organismo vivo que se interliga a um projeto de sociedade onde não mais se justifica a produção do conhecimento como ações isoladas, desagregadas e despolitizadas. Sua função deve estar atrelada a um projeto político-pedagógico emancipatório e não pode mais consistir em uma prática enquanto especialidade e ações isoladas. Vinculam-se a democratização do poder e das relações entre os sujeitos, as quais darão sentido a sua missão histórica.

Resgatar a práxis reflexiva ao invés de reforçar a cultura da gerência, própria da concepção empresarial da pesquisa em política educacional nos parece condição fundamental para recuperar o valor e a importância desse intelectual com capacidade de organicidade a um projeto político pedagógico emancipatório.

Contudo, a sociedade contemporânea apresenta mudanças preocupantes. A 


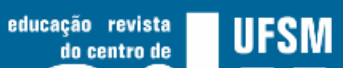 Eltuarao}

desagregação dos valores éticos e políticos individualizam a busca de alternativas, pois o sucesso ou insucesso passa a ser de responsabilidade individual. Valem mais os interesses pessoais e imediatos dos indivíduos do que princípios voltados para a vida coletiva. A sociedade do salve-se quem puder expõe sua fragilidade e dificulta ações consensuais democráticas e participativas acentuadamente. Para Marx, só a luta de classe revela a existência desse movimento. Esta é que permite a mudança das condições materiais, modificando e criando novas relações sociais. O processo de luta se dá no âmbito da organização social da produção capitalista, pois é nesse momento que se contrapõem dominantes e dominados. As classes dominantes monopolizam a ciência, a arte e a dimensão mais ampliada da cultura. A ciência passa a ser um instrumento de apropriação cultural e espiritual nas mãos da classe dominante que a usará como meio de extorsão da mais valia.

O conhecimento apresenta-se como uma ferramenta de múltiplos usos políticos. Ele tem tanto o caráter político estratégico ou libertário e o de mercadoria no sentido de se fazer valer os interesses econômicos dos capitalistas. O poder emancipatório, em sua capacidade de incrementar o diálogo e as possibilidades de ação da coletividade, passaria pela ideia de que ao mesmo tempo em que a ciência deve romper com o senso comum no sentido de se desenvolver analítica e formalmente, ela deve retornar ao senso comum enquanto disponibilidade e acessibilidade, ainda que seu registro formal deva ser traduzido para uma linguagem mais funcional. Contudo, há quem pense que ao servir aos interesses imediatos dos dominantes, a Educação tenderia a médio ou longo prazo, ou ainda de modo indireto, a favorecer a toda comunidade, pois o desenvolvimento social em seus mais variados aspectos passaria pelo incremento das privatizações. Essa visão traz em si o preconceito de que apenas a Escola Privada seria uma instância de auto-organização, capaz de agenciar saber e promover benefícios comuns. Assim, a diferenciação de público e privado seria meramente formal pois, na prática, o agente do bem público não seria o governo, muito menos entidades não lucrativas, quer dizer, auto organizacionais, cooperativas, nem no sentido puro, tampouco no misto, combinando benefícios imediatos em termos de melhorias do nível de vida dos seus participantes e ainda com fins lucrativos. 


\section{Disn \\ ISSN: 1984-6444

Por outro lado, perde-se a capacidade de compreender a realidade. E aqui não se trata de que não se deve pensar e refletir sobre modos de transformar a realidade... mas de onde sai a função transformadora de compreendê-la? O que faz um investigador, um intelectual compreender a realidade?

Os fundamentos científicos, metodológicos, filosóficos e pedagógicos da proposta apresentada pelo Estado, ainda que sejam importantes no questionamento da tradicional forma de integração das disciplinas, e no resgate de temas como a ética e a justiça, ao propor a fragmentação e o pluralismo dos saberes, tornam a escola mais um cenário midiático, com forte apelo às estratégias televisivas de entretenimento, em que não especialistas falam sobre tudo. A crise das ciências e das especialidades, enquanto sintoma da superação do positivismo é um bom sinal, mas a substituição da organização das grades curriculares tradicionais por saberes não científicos é questionável, pois abriria a possibilidade de a escola tornar-se o lugar em que os preconceitos e a superficialidade no tratamento de temas relevantes para a humanidade assumiriam uma dimensão temerária.

\section{Referências}

ALVES, N. Sobre a possibilidade e a necessidade curricular de uma base nacional comum. Revista Científica e-Curriculum, v. 12, n. 3, p. 1464-1479, 2014.

BIANCHETTI, R. Modelo neoliberal e políticas educacionais, São Paulo, Cortez, 1996.

BRASIL. Lei CNE no 9.131, de 24 de novembro de 1995. Altera dispositivos da Lei no 4.024, de 20 de dezembro de 1961, e dá outras providências. Brasília: 24 de novembro de 1995. Disponível em: http://www.planalto.gov.br/ccivil_03/leis/L9131.htm>. Acesso em: 29 ago. 2016.

BRASIL. Presidência da República. Lei n. 9.394, de 20 de dezembro de 1996. Estabelece as diretrizes e bases da educação nacional. Brasília: 20 de dezembro de 1996. Disponível em: < www.planalto.gov.br/ccivil_03/LEIS/I9394.htm>. Acesso em: 06 fev. 2016.

BRASIL. Plano Nacional de Educação 2014-2024. Lei no 13.005, de 25 de junho de 2014. Disponível em < http://www.planalto.gov.br/ccivil_03/_ato2011-2014/2014/lei/l13005.htm>. Acesso em: 06 abr. 2016.

CHERRYHOLMES, C. Power and criticismo: poststructural investigations in education. New York: Teachers College Press, 1988. p. 149. 


\section{Tusm \\ ISSN: 1984-6444

GRAMSCI, A. Cuadernos de la Cárcel. Edición Crítica del Instituto Gramsci a cargo de Valentino Gerratana. Tomo 5. Trad. Ana María Palos. Coedición Ediciones Era / Benemérita Universidad Autónoma de Puebla: México, D.F, 1999.

HUNT, Ed.; SHERMAN, H. História do Pensamento Econômico. R.J. Ed. Vozes. 1977. JUNG, H. S.; SUDBRACK, E. M. Pátria educadora ou Pátria panóptica? Revista Cocar, v. 10, n. 19, p. 265-286, 2016.

KOSIK, K. Dialética do Concreto. Tradução de Célia Neves e Alderico Toríbio. $2^{\underline{a}}$ ed. Rio de Janeiro: Paz e Terra, 1976.

NASSIF, L. In: Folha de São Paulo, 14/10/97.

OLIVEIRA, V. B. (ORG.). Informática em Psicopedagogia, S.P. Editora SENAC. 1996.

PETITAT, A. A produção da escola, produção da sociedade: Análise sócio-histórica de alguns momentos decisivos da evolução escolar no Ocidente. Porto Alegre: Artes Médicas, 1994.

ROIO, M. A educação como forma de reprodução da hegemonia e seu avesso. In:

SCHLESENER, Anita. (ORG.) Filosofia, Política e Educação: leituras de Antônio Gramsci. Curitiba: UTP, 2014.

SAVIANI, D. Educação e questões da atualidade. S.P. Livros do Tatu, ed. Cortez, 1993

SMITH, A. A riqueza das nações, S.P. Nova Cultural. 1985, vol. I, p. 50.

SOUZA, R. F. Inovação educacional no século XIX: A construção do currículo da escola primária no Brasil. Cadernos Cedes, ano XX, no 51, novembro/2000.

TURCHI, L. M. Qualidade total: afinal, de que estamos falando? Texto para discussão número 459. IPE, Ministério do Planejamento e Orçamento. Brasília: fev. 1997.

\section{Correspondência}

Maria de Lourdes Pinto de Almeida - Professora doutora da Universidade do Oeste de Santa Catarina, Joaçaba, Santa Catarina, Brasil.

Hildegard Susana Jung - Doutora em Educação pela Universidade La Salle, Canoas, Rio Grande do Sul, Brasil.

Universidade do Oeste de Santa Catarina, Programa de Pós Graduação em Educação

- Campus de Joaçaba. Rua Getulio Vargas 2125, Flor da Serra. CEP:

89600000. Joaçaba, Santa Catarina, Brasil.

E-mail: malu04@gmail.com - hildegardsjung@gmail.com 
Recebido em 22 de abril de 2017

Aprovado em 08 de março de 2018

educação | Santa Maria | v. 00 | n. 00 | p. 00-000 | 000./000. 2018 - ISSN: 1984-6444 